\title{
A New Approach of Generalized Pre-Closed Sets With Respect to an Ideal
}

\author{
Dr.P.Maheshwaran, Assistant Professor, Vivekananda College, Agasteeswaram, India, \\ pmeshwar@gmail.com
}

\begin{abstract}
An ideal on a set $\mathrm{X}$ is a non empty collection of subsets of $\mathrm{X}$ with heredity property which is also closed under finite unions. The concept of generalized closed sets was introduced by Levine. In this paper, I introduce and investigate the concept of generalized pre-closed sets with respect to an ideal
\end{abstract}

Keywords - g-closed sets, gp-closed sets, Ig-closed sets, Igp-closed sets, ideal, Topological spaces.

\section{INTRODUCTION}

Indeed ideals are very important tools in General Topology. It was the works of Newcomb[8], Rancin [9], Samuels [10] and Hamlet and Jankovic (see [1, 2, 3, 4, 5]) which motivated the research in applying topological ideals to generalize the most basic properties in General Topology. A nonempty collection I of subsets on a topological space $(\mathrm{X}, \tau)$ is called a topological ideal [6] if it satisfies the following two conditions:

1. If $\mathrm{A} \in \mathrm{I}$ and $\mathrm{B} \subset \mathrm{A}$ implies $\mathrm{B} \in \mathrm{I}$ (heredity)

2. If $A \in I$ and $B \in I$, then $A \cup B \in I$ (finite additively)

If $\mathrm{A}$ is a subset of a topological space $(\mathrm{X}, \tau), \operatorname{cl}(\mathrm{A})$ and int(A) denote the closure of $A$ and the interior of $A$, respectively. Let $\mathrm{A} \subset \mathrm{B} \subset \mathrm{X}$. Then $\mathrm{cl}_{\mathrm{B}}(\mathrm{A})\left(\operatorname{resp}_{\mathrm{Bnt}}(\mathrm{A})\right)$ denotes closure of $A$ (resp. interior of $A$ ) with respect to $B$. Levine [7] introduced the concept of generalized closed sets. This notion has been studied extensively in recent years by many topologists.

\section{PRELIMINARIES}

Definition 2.1. A subset A of a topological space $(X, \tau)$ is said to be generalized closed (briefly g-closed) if $\operatorname{cl}(\mathrm{A}) \subset \mathrm{U}$ whenever $A \subset U$ and $U$ is open in $(X, \tau)$.

Definition 2.2. A subset A of a topological space $(X, \tau)$ is said to be generalized pre-closed (briefly gp-closed) if $\operatorname{pcl}(\mathrm{A}) \subset \mathrm{U}$ whenever $\mathrm{A} \subset \mathrm{U}$ and $\mathrm{U}$ is open in $(\mathrm{X}, \tau)$.

Definition 2.3. Let $(X, \tau)$ be a topological space and I be an ideal on $\mathrm{X}$. A subset $\mathrm{A}$ of $\mathrm{X}$ is said to be generalized closed with respect to an ideal (briefly Ig-closed) if and only if $\operatorname{cl}(\mathrm{A})-\mathrm{U} \in \mathrm{I}$, whenever $\mathrm{A} \subset \mathrm{U}$ and $\mathrm{U}$ is open in $(\mathrm{X}, \tau)$.

In this paper, I introduce and study the concept of gp-closed sets with respect to an ideal, which is the extension of the concept of g-closed sets.

\section{GENERALIZED PRE-CLOSED SETS WITH RESPECT TO AN IDEAL}

Definition 3.1 Let $(X, \tau)$ be a topological space and I be an ideal on $\mathrm{X}$. A subset $\mathrm{A}$ of $\mathrm{X}$ is said to be generalized preclosed with respect to an ideal (briefly Igp-closed) if and only if $\operatorname{pcl}(\mathrm{A})-\mathrm{U} \in \mathrm{I}$, whenever $\mathrm{A} \subset \mathrm{U}$ and $\mathrm{U}$ is open in $(\mathrm{X}, \tau)$.

Remark 3.1 Every g-closed set is Igp-closed, but the converse need not be true, as this may be seen from the following example.

Example 1. Let $X=\{a, b, c\}$ with topology $=\{\Phi$, $\{a\},\{c\},\{a, c\}, X\}$ and $I=\{\Phi,\{a\},\{b\},\{a, b\}\}$.Clearly, the set $\{a\}$ is Igp-closed but not g-closed in $(X, \tau)$.

Remark 3.2 Every gp-closed set is Igp-closed, but the converse need not be true, as this may be seen from the following example.

Example 2. Let $X=\{a, b, c\}$ with topology $=\{\Phi$, $\{a\},\{c\},\{a, c\}, X\}$ and $I=\{\Phi,\{a\},\{b\},\{a, b\}\}$.Clearly, the set $\{a, c\}$ is Igp-closed but not gp-closed in $(X, \tau)$.

Theorem 3.1. A set A is Igp-closed in $(X, \tau)$ if and only if $F$ $\subset \operatorname{pcl}(\mathrm{A})-\mathrm{A}$ and $\mathrm{F}$ is closed in $\mathrm{X}$ implies $\mathrm{F} \in \mathrm{I}$.

Proof. Let A be Igp-closed. Suppose that $F \subset \operatorname{pcl}(A)-A$. If $F$ is closed then $A \subset X-F$. Since $A$ is Igp-closed. Then $\operatorname{pcl}(\mathrm{A})-(\mathrm{X}-\mathrm{F}) \in \mathrm{I}$. But $\mathrm{F} \subset \operatorname{pcl}(\mathrm{A})-(\mathrm{X}-\mathrm{F})$ and hence $\mathrm{F}$ $\in$ I.Conversely, Assume that $F \subset \operatorname{pcl}(\mathrm{A})-\mathrm{A}$ and $\mathrm{F}$ is closed in $X$ implies that $F \in I$. Suppose $A \subset U$ and $U$ is open. Then $\operatorname{pcl}(\mathrm{A})-\mathrm{U}=\operatorname{pcl}(\mathrm{A}) \cap(\mathrm{X}-\mathrm{U}) \subset \operatorname{pcl}(\mathrm{A})-$ A. But $\operatorname{pcl}(A)-U$ is closed. By assumption, $\operatorname{pcl}(A)-U \in I$. Hence A is Igp-closed

Theorem 3.2. If $A$ and $B$ are Igp-closed sets of $(X, \tau)$, then their union A $U$ B is also Igp-closed.

Proof. Let A and B be Igp-closed sets in $(X, \tau)$.If $A \cup B \subset$ $U$ and $U$ is open, then $A \subset U$ and $B \subset U$. Since $A$ and $B$ is Igp-closed sets. Then $\operatorname{pcl}(\mathrm{A})-\mathrm{U} \in \mathrm{I}$ and $\operatorname{pcl}(\mathrm{B})-\mathrm{U} \in \mathrm{I}$ 
and hence $\operatorname{pcl}(\mathrm{A} \cup \mathrm{B})-\mathrm{U}=(\operatorname{pcl}(\mathrm{A})-\mathrm{U}) \mathrm{U}(\operatorname{pcl}(\mathrm{B})-\mathrm{U}) \in \mathrm{I}$. That is A U B is Igp-closed.

Theorem 3.3. If A and B are Igp-closed sets of $(X, \tau)$, then their intersection $\mathrm{A} \cap \mathrm{B}$ is also Igp-closed.

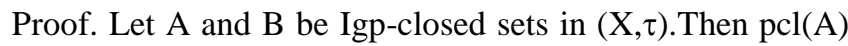
$-\mathrm{U} \in \mathrm{I}$ whenever $\mathrm{A} \subset \mathrm{U}$ and $\mathrm{U}$ is open and $\operatorname{pcl}(\mathrm{B})-\mathrm{U} \in \mathrm{I}$ whenever $\mathrm{B} \subset \mathrm{U}$ and $\mathrm{U}$ is open and hence $\operatorname{pcl}(\mathrm{A} \cap \mathrm{B})-\mathrm{U}$ $=(\operatorname{pcl}(\mathrm{A})-\mathrm{U}) \cap(\operatorname{pcl}(\mathrm{B})-\mathrm{U}) \in \mathrm{I}$ whenever $\mathrm{A} \cap \mathrm{B} \subset \mathrm{U}$ and $\mathrm{U}$ is open . That is $\mathrm{A} \cap \mathrm{B}$ is Igp-closed.

Theorem 3.4. If $A$ is Igp-closed and $A \subset B \subset \operatorname{pcl}(A)$ in $(\mathrm{X}, \tau)$, then $\mathrm{B}$ is Igp-closed in $(\mathrm{X}, \tau)$.

Proof. Let A is Igp-closed and $\mathrm{A} \subset \mathrm{B} \subset \operatorname{pcl}(\mathrm{A})$ in $(\mathrm{X}, \tau)$.Suppose $\mathrm{B} \subset \mathrm{U}$ and $\mathrm{U}$ is open. Then $\mathrm{A} \subset \mathrm{U}$. Since $\mathrm{A}$ is Igp-closed, then we have $\operatorname{pcl}(\mathrm{A})-\mathrm{U} \in \mathrm{I}$. Now $\mathrm{B} \subset \operatorname{pcl}(\mathrm{A})$. This implies that $\operatorname{pcl}(\mathrm{B})-\mathrm{U} \subset \operatorname{pcl}(\mathrm{A})-\mathrm{U} \in \mathrm{I}$. Hence $\mathrm{B}$ is Igp-closed in $(\mathrm{X}, \tau)$.

Theorem 3.5. Let $A \subset Y \subset X$ and $A$ be Igp-closed in $(X, \tau)$. Then A is Igp-closed relative to the subspace $\mathrm{Y}$ of $\mathrm{X}$, with respect to the ideal $I_{Y}=\{F \subset Y: F \in I\}$.

Proof. Let $\mathrm{A} \subset \mathrm{U} \cap \mathrm{Y}$ and $\mathrm{U}$ be open in $(\mathrm{X}, \tau)$, then $\mathrm{A} \subset \mathrm{U}$. Since $A$ is Igp-closed in $(X, \tau)$, we have $\operatorname{pcl}(\mathrm{A})-\mathrm{U} \in \mathrm{I}$. $(\operatorname{pcl}(\mathrm{A}) \cap \mathrm{Y})-(\mathrm{U} \cap \mathrm{Y})=(\operatorname{pcl}(\mathrm{A})-\mathrm{U}) \cap \mathrm{Y} \in \mathrm{I}$, whenever $\mathrm{A} \subset \mathrm{U} \cap \mathrm{Y}$ and $\mathrm{U}$ is open. Hence $\mathrm{A}$ is Igp-closed relative to the subspace $Y$.

Theorem 3.6. Let A be an Igp-closed set and F be a closed set in $(X, \tau)$, then $A \cap F$ is an Igp-closed set in $(X, \tau)$.

Proof. Let A be an Igp-closed set and in (X, $\tau)$.Then $\operatorname{pcl}(\mathrm{A})$ $-\mathrm{U} \in \mathrm{I}$, whenever $\mathrm{A} \subset \mathrm{U}$ and $\mathrm{U}$ is open. Let $\mathrm{F}$ be a closed set in $(\mathrm{X}, \tau)$. Since Every closed set is Igp-closed. Hence $\mathrm{F}$ is Igp-closed. By theorem 3.3, intersection of any two Igp-closed sets is also Igp-closed. Thus $\mathrm{A} \cap \mathrm{F}$ is an Igpclosed set in $(\mathrm{X}, \tau)$.

Remark 3.3. The following diagram holds for any subset of a topological space $(\mathrm{X}, \tau)$ with respect to an ideal

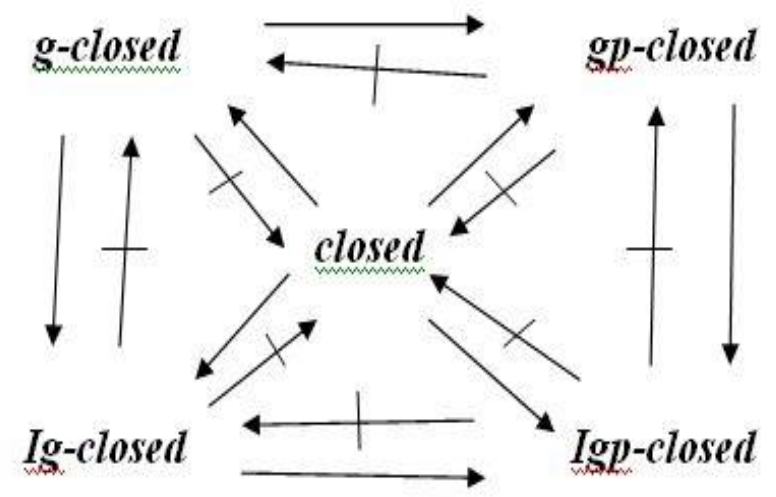

Definition 3.2. Let $(X, \tau)$ be a topological space and I be an ideal on $\mathrm{X}$. A subset $\mathrm{A} \subset \mathrm{X}$ is said to be generalized pre- open with respect to an ideal (briefly Igp-open) if and only if $\mathrm{X}-\mathrm{A}$ is Igp-closed.

Theorem 3.7. A set A is Igp-open in $(X, \tau)$ if and only if $F-$ $\mathrm{U} \subset \operatorname{pint}(\mathrm{A})$, for some $\mathrm{U} \in \mathrm{I}$, whenever $\mathrm{F} \subset \mathrm{A}$ and $\mathrm{F}$ is closed.

Proof. Let A be Igp-open. Suppose F $\subset \mathrm{A}$ and $\mathrm{F}$ is closed. We have $\mathrm{X}-\mathrm{A} \subset \mathrm{X}-\mathrm{F}$. Since A is Igp-open Then pcl(XA) $\subset(X-F) \cup U$, for some $U \in I$. This implies $X-((X-F) U$ $\mathrm{U}) \subset \mathrm{X}-(\mathrm{pcl}(\mathrm{X}-\mathrm{A}))$ and hence $\mathrm{F}-\mathrm{U} \subset \operatorname{pint}(\mathrm{A})$.Conversely, assume that $\mathrm{F} \subset \mathrm{A}$ and $\mathrm{F}$ is closed imply $\mathrm{F}-\mathrm{U} \subset \operatorname{pint}(\mathrm{A})$, for some $\mathrm{U} \in \mathrm{I}$. Consider an open set $\mathrm{H}$ such that $\mathrm{X}-\mathrm{A} \subset \mathrm{H}$. Then $\mathrm{X}-\mathrm{H} \subset \mathrm{A} . \quad \mathrm{By}$ assumption, $(\mathrm{X}-\mathrm{H})-\mathrm{U} \subset \operatorname{pint}(\mathrm{A})=\mathrm{X}-\operatorname{pcl}(\mathrm{X}-\mathrm{A})$. This gives that $\mathrm{X}-(\mathrm{H} \cup \mathrm{U}) \subset \mathrm{X}-\operatorname{pcl}(\mathrm{X}-\mathrm{A})$. Then, $\operatorname{pcl}(\mathrm{X}-\mathrm{A}) \subset \mathrm{H} \cup \mathrm{U}$, for some $U \in I$. This shows that $p c l(X-A)-G \in I$. Hence $X-A$ is Igp-closed.

Theorem 3.8. If $\mathrm{A} \subset \mathrm{Y} \subset \mathrm{X}, \mathrm{A}$ is Igp-open relative to $\mathrm{Y}$ and $\mathrm{Y}$ is Igp-open relative to $\mathrm{X}$, then $\mathrm{A}$ is Igp-open relative to $\mathrm{X}$.

Proof. Suppose $\mathrm{A} \subset \mathrm{Y} \subset \mathrm{X}$, A is Igp-open relative to $\mathrm{Y}$ and $\mathrm{Y}$ is Igp-open relative to $\mathrm{X}$. Suppose $\mathrm{H} \subset \mathrm{A}$ and $\mathrm{H}$ is closed. A is Igp-open relative to $\mathrm{Y}$, by Theorem 3.7, $\mathrm{H}-U \subset$ $\operatorname{pint}_{Y}(\mathrm{~A})$, for some $U \in \mathrm{I}$. This implies there exists an open set $G$ such that $\mathrm{H}-U \subset G \cap \mathrm{Y} \subset \mathrm{A}$, for some $U \in \mathrm{I}$. Since $\mathrm{Y}$ is Igp-open relative to $\mathrm{X}, \mathrm{H} \subset \mathrm{Y}$ and $\mathrm{H}$ is closed; we have $\mathrm{F}-V \subset \operatorname{pint}(\mathrm{Y})$, for some $V \in \mathrm{I}$. This implies there exists an open set $K$ such that $\mathrm{H}-V \subset K \subset \mathrm{Y}$, for some $V \in \mathrm{I}$. Now $\mathrm{H}-(U \cup V) \subset(\mathrm{H}-U) \cap(\mathrm{H}-V) \subset G \cap K \subset G \cap \mathrm{Y} \subset \mathrm{A}$. This implies that $\mathrm{H}-(U \cup V) \subset \operatorname{pint}(\mathrm{A})$, for some $U \cup V \in$ $\mathrm{I}$ and hence $\mathrm{A}$ is Igp-open relative to $\mathrm{X}$.

Theorem 3.9. Let pint $(\mathrm{A}) \subset \mathrm{B} \subset \mathrm{A}$ and $\mathrm{A}$ be Igp-open in $(X, \tau)$, then $B$ is Igp-open in $X$.

Proof. Let pint $(\mathrm{A}) \subset \mathrm{B} \subset \mathrm{A}$ and $\mathrm{A}$ be Igp-open in $(\mathrm{X}, \tau)$. Then $\mathrm{X}-\mathrm{A} \subset \mathrm{X}-\mathrm{B} \subset \mathrm{pcl}(\mathrm{X}-\mathrm{A})$ and $\mathrm{X}-\mathrm{A}$ is Igp-closed. By Theorem 3.4, $\mathrm{X}-\mathrm{B}$ is Igp-closed and hence $\mathrm{B}$ is Igpopen.

Theorem 3.10. A set A is Igp-closed in $(X, \tau)$ if and only if pcl(A)-A is Igp-open.

Proof. Suppose $\mathrm{F} \subset \operatorname{pcl}(\mathrm{A})-\mathrm{A}$ and $\mathrm{F}$ is closed. Then $\mathrm{F} \in$ I.This implies that $\mathrm{F}-\mathrm{U}=\Phi$ for some $\mathrm{U} \in \mathrm{I}$. Clearly, $\mathrm{F}-\mathrm{U}$ $\subset \operatorname{pint}(\operatorname{pcl}(\mathrm{A})-\mathrm{A})$. By Theorem 3.7, $\operatorname{pcl}(\mathrm{A})-\mathrm{A}$ is Igpopen.Conversely, Suppose $A \subset G$ and $G$ is open in $(X, \tau)$. Then $\operatorname{pcl}(\mathrm{A}) \cap(\mathrm{X}-\mathrm{G}) \subset \operatorname{pcl}(\mathrm{A}) \cap(\mathrm{X}-\mathrm{A})=\operatorname{pcl}(\mathrm{A})-\mathrm{A}$. By hypothesis, $\quad(\operatorname{pcl}(\mathrm{A}) \cap(\mathrm{X}-\mathrm{G}))-\mathrm{U} \subset \operatorname{pint}(\alpha \operatorname{cl}(\mathrm{A})-\mathrm{A})=\Phi$ for some $\mathrm{U} \in \mathrm{I}$. This implies that $\operatorname{pcl}(\mathrm{A}) \cap(\mathrm{X}-\mathrm{G}) \subset \mathrm{U} \in \mathrm{I}$ and hence $\operatorname{pcl}(\mathrm{A})-\mathrm{G} \in \mathrm{I}$. Thus, $\mathrm{A}$ is Igp-closed.

Theorem 3.11. Let $\mathrm{f}:(\mathrm{X}, \tau) \rightarrow(\mathrm{Y}, \sigma)$ be continuous and closed. If $A \subset X$ is Igp-closed in $X$, then $f(A)$ is $f(I)$-gpclosed in $(Y, \sigma)$, where $f(I)=\{f(U): U \in I\}$. 
Proof. Let $A \subset X$ and $A$ be Igp-closed. Suppose $f(A) \subset G$ and $G$ is open. Then $A \subset f^{-1}(G)$. By definition, $\operatorname{pcl}(A)-$ $f^{-1}(G) \in I$ and hence $f(p c l(A))-G \in f(I)$. Since $f$ is closed, $\operatorname{pcl}(\mathrm{f}(\mathrm{A})) \subset \operatorname{pcl}(\mathrm{f}(\operatorname{pcl}(\mathrm{A})))=\mathrm{f}(\operatorname{pcl}(\mathrm{A}))$. Then $\operatorname{pcl}(\mathrm{f}(\mathrm{A}))-\mathrm{G} \subset$ $f(\operatorname{pcl}(A))-G \in f(I)$ and hence $f(A)$ is $f(I)$-gp-closed.

\section{Conclusion}

Our work is an step forward to strengthen the theoretical foundation of topological spaces of generalized pre-closed with respect to an ideal. For further work one can quickly go for application of these theoretical developments, I list some important topics for further theoretical work.

\section{ACKNOWLEDGMENT}

The author is grateful to the editor and the referee(s) for their fruitful comments, valuable suggestions and careful corrections.
[12]Dr.P.Maheshwaran, $\alpha$ Generalized Closed Sets with respect to an Ideal, Wutan Huatan Jisuan Jishu, Volume XVI, Issue V, May/2020, Page No: 332-336

[13]Dr.P.Maheshwaran, Pre-Generalized Closed Sets with respect to an Ideal, Strad Research, VOLUME 7, ISSUE 6, 2020, Page No: 172-175

\section{REFERENCES}

[1] T. R. Hamlett and D. Jankovic, Compactness with respect to an ideal, Boll. Un. Mat. Ita.,(7), 4-B, 849861. 1990 .

[2] T. R. Hamlett and D. Jankovic, Ideals in topological spaces and the set operator, Boll Un. Mat. Ita., 7, 863874. 1990.

[3] T. R. Hamlett and D. Jankovic, Ideals in General Topology and Applications (Midletown, CT, 1988), 115-125, Lecture Notes in Pure and Appl. Math. Dekker, New York, 1990.

[4] T. R. Hamlett and D. Jankovic, Compatible extensions of ideals, Boll. Un. Mat. Ita., 7,453-465. 1992..

[5] D. Jankovic and T. R. Hamlett, New topologies from old via ideals, Amer. Math. Month.,97, 295-310. 1990.

[6] K. Kuratowski, Topologies I, Warszawa, 1933.

[7] . Levine, Generalized closed sets in topology, Rend. Circ. Mat. Palermo, 19(2), 89-96.1970.

[8] R. L. Newcomb, Topologies which are compact modulo an ideal, Ph.D. Dissertation,Univ. Cal. at Santa Barbara, 1967.

[9] D. V. Rancin, Compactness modulo an ideal, Soviet Math. Dokl., 13, 193-197. 1972.

[10] P. Samuels, A topology from a given topology and ideal, J. London Math. Soc. (2)(10),409-416. 1975

[11]Dr.P.Maheshwaran, Generalized $\alpha$ Closed Sets with respect to an Ideal, The International journal of analytical and experimental modal analysis, Volume XII, Issue V, May/2020, Page No:400-403 